\section{Ka mua, ka muri: \\ Navigating the future of design education by drawing upon indigenous frameworks}

\section{Zak Waipara}

Auckland University of Technology

We have not yet emerged into a post-COVID world. The future is fluid and unknown. As the Academy morphs under pressure, as design practitioners and educators attempt to respond to the shifting world - in the Māori language, Te Ao Hurihuri - how might we manage such changes?

There is an indigenous precedent of drawing upon the past to assist with present and future states - as the proverb ka mua ka muri indicates, 'travelling backwards into the future,' viewing the past spread out behind us, as we move into the unknown. Indigenous academics often draw inspiration from extant traditional viewpoints, reframing them as methodologies, and drawing on metaphor to shape solutions. Some of these frameworks, such as Te Whare Tapa Whā, developed as a health-based model, have been adapted for educational purposes. Many examples of metaphor drawn from indigenous ways of thinking have also been adapted as design or designrelated methodologies.

What is it about the power of metaphor, particularly indigenous

ways of seeing, that might offer solutions for both student and teacher?

One developing propositional model uses the Pacific voyager as exemplar for the student. Hohl cites Polynesian navigation an inspirational metaphor, where "navigating the vast Pacific Ocean without instruments, only using the sun, moon, stars, swells, clouds and birds as orienting cues to travel vast distances between Polynesian islands." ${ }^{1}$ However, in these uncertain times, it becomes just as relevant for the academic staff member. As Reilly notes, using this analogy to situate two cultures working as one: "like two canoes, lashed together to achieve greater stability in the open seas ... we must work together to ensure our ship keeps pointing towards calmer waters and to a future that benefits subsequent generations."2
Orcid number

0000-0002-7535-5768
The goal in formulating this framework has been to extract guiding principles and construct a useful, applicable structure by drawing from research on two existing models based in Samoan and Hawaiian worldviews, synthesised via related Māori concepts.

Just as we expect our students to stretch their imaginations and challenge themselves, we the educators might also find courage in the face of the unknown, drawing strength from indigenous storytelling. Hohl describes the advantages of examining this approach: "People living on islands are highly aware of the limitedness of their resources, the precarious balance of their natural environment and the long wearing negative effects of unsustainable actions ... from experience and observing the consequences of actions in a limited and confined environment necessarily lead to a sustainable culture in order for such a society to survive." ${ }^{3}$ Calculated risks must be undertaken to navigate this space, as shown in this waka-navigator framework, adapted for potential use in a collaborative, studio-style classroom model.

\section{KEYWORDS}

Design, Education, Mātauranga Māori, Metaphors, Polynesian Navigation 